\title{
Nuclear energy: assessing the emissions
}

\section{Kurt Kleiner reports on whether nuclear power deserves its reputation as a low-carbon energy source.}

or decades nuclear power has been slated as being environmentally harmful. But with climate change emerging as the world's top environmental problem, the nuclear industry is now starting to enjoy a reputation as a green power provider, capable of producing huge amounts of energy with little or no carbon emissions ${ }^{1}$. As a result, the industry is gaining renewed support. In the United States, both presidential candidates view nuclear power as part of the future energy mix. The US government isn't alone in its support for an expansion of nuclear facilities. Japan announced in August that it would spend $\$ 4$ billion on green technology, including nuclear plants.

But despite the enthusiasm for nuclear energy's status as a low-carbon

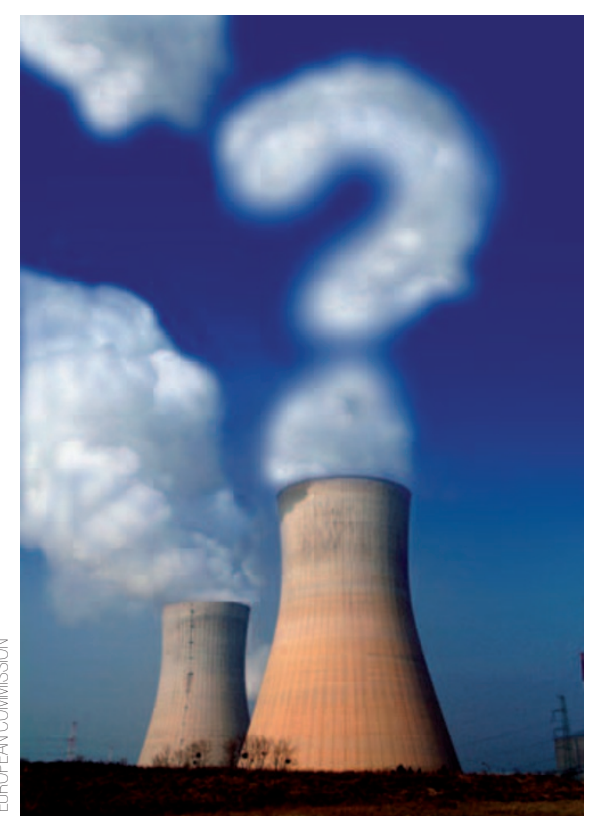

Estimates of the emissions associated with producing nuclear energy vary widely. technology, the greenhouse gas emissions of nuclear power are still being debated. While it's understood that an operating nuclear power plant has near-zero carbon emissions (the only outputs are heat and radioactive waste), it's the other steps involved in the provision of nuclear energy that can increase its carbon footprint. Nuclear plants have to be constructed, uranium has to be mined, processed and transported, waste has to be stored, and eventually the plant has to be decommissioned. All these actions produce carbon emissions.

Critics claim that other technologies would reduce anthropogenic carbon emissions more drastically, and more cost effectively. "The fact is, there's no such thing as a carbon-free lunch for any energy source," says Jim Riccio, a nuclear policy analyst for Greenpeace in Washington DC. "You're better off pursuing renewables like wind and solar if you want to get more bang for your buck." The nuclear industry and many independent analysts respond that the numbers show otherwise. Even taking the entire lifecycle of the plant into account nuclear energy still ranks with other green technologies, like solar panels and wind turbines, they say.

\section{LIFE STUDIES}

Evaluating the total carbon output of the nuclear industry involves calculating those emissions and dividing them by the electricity produced over the entire lifetime of the plant. Benjamin K. Sovacool, a research fellow at the National University of Singapore, recently analyzed more than one hundred lifecycle studies of nuclear plants around the world, his results published in August in Energy Policy ${ }^{2}$. From the 19 most reliable assessments, Sovacool found that estimates of total lifecycle carbon emissions ranged from 1.4 grammes of carbon dioxide equivalent per kilowatt-hour $\left(\mathrm{gCO}_{2} \mathrm{e} / \mathrm{kWh}\right)$ of electricity produced up to $288 \mathrm{gCO}_{2} \mathrm{e} / \mathrm{kWh}$. Sovacool believes the mean of $66 \mathrm{gCO}_{2} \mathrm{e} / \mathrm{kWh}$ to be a reasonable approximation.

\section{"For every dollar you spend on nuclear, you could have saved five or six times as much carbon with efficiency, or wind farms."}

Benjamin Sovacool

The large variation in emissions estimated from the collection of studies arises from the different methodologies used - those on the low end, says Sovacool, tended to leave parts of the lifecycle out of their analyses, while those on the high end often made unrealistic assumptions about the amount of energy used in some parts of the lifecycle. The largest source of carbon emissions, accounting for 38 per cent of the average total, is the "frontend" of the fuel cycle, which includes mining and milling uranium ore, and the relatively energyintensive conversion and enrichment process, which boosts the level of uranium-235 in the fuel to useable levels. Construction (12 per cent), operation (17 per cent largely because of backup generators using fossil fuels during downtime), fuel processing and waste disposal (14 per cent) and decommissioning (18 per cent) make up the total mean emissions.

According to Sovacool's analysis, nuclear power, at $66 \mathrm{gCO}_{2} \mathrm{e} / \mathrm{kWh}$ emissions is well below scrubbed coal-fired plants, which emit $960 \mathrm{gCO}_{2} \mathrm{e} / \mathrm{kWh}$, and natural gas-fired plants, at $443 \mathrm{gCO}_{2} \mathrm{e} / \mathrm{kWh}$. However, nuclear emits twice as much carbon as solar photovoltaic, at $32 \mathrm{gCO}_{2} \mathrm{e} / \mathrm{kWh}$, and six times as much as onshore wind farms, at $10 \mathrm{gCO}_{2} \mathrm{e} / \mathrm{kWh}$. "A number in the $60 \mathrm{~s}$ 
puts it well below natural gas, oil, coal and even clean-coal technologies. On the other hand, things like energy efficiency, and some of the cheaper renewables are a factor of six better. So for every dollar you spend on nuclear, you could have saved five or six times as much carbon with efficiency, or wind farms," Sovacool says. Add to that the high costs and long lead times for building a nuclear plant about $\$ 3$ billion for a 1,000 megawatt plant, with planning, licensing and construction times of about 10 years and nuclear power is even less appealing.

\section{POWER GAMES}

But, says Paul Genoa, director of policy development for the Nuclear Energy Institute (NEI), a nuclear industry association based in Washington DC, "it's a fallacy to say one energy source is better, and that we should use it everywhere. The reality is that we need a portfolio solution that will include nuclear."

"If you look at lifecycle emissions from renewable technologies, typically they are on the order of only 1 to 5 per cent of a coal plant," says Paul Meier, director of the Energy Institute at the University of Wisconsin-Madison. Looked at as a replacement for fossil fuels, existing nuclear plants prevent 681 million tonnes of carbon from being emitted every year in the United States alone, according to the NEI.

Meier also points out that nuclear energy is capable of providing baseload power - that is, large amounts of power that can run consistently and reliably. Nuclear plants run 90 per cent of the time, while wind and solar power provide electricity only intermittently and have to be backed up, often by fossil fuel plants. "The modern electric grid relies on baseload power," says Genoa. “That's power that's running 24 hours a day, 365 days a year. It's only shut down for maintenance." Money spent on energy efficiency, however, is equivalent to increasing baseload power, since it reduces the overall power that needs to be generated, says Sovacool. And innovative energy-storage solutions, such as compressed air storage, could provide ways for renewables to provide baseload power.

\section{"The fact is, there's no such thing as a carbon-free lunch for any energy source." Jim Riccio}

Thomas Cochran, a nuclear physicist and senior scientist at the Natural Resources Defense Council (NRDC), an environmental group in Washington DC, says that although nuclear power has relatively low carbon emissions, it should not be subsidized by governments in the name of combating global warming. He argues that the expense and risk of building nuclear plants makes them uneconomic without large government subsidies, and that similar investment in wind and solar photovoltaic power would pay off sooner. "There are appropriate roles for federal subsidies in energy technologies," he says. "We subsidized heavily nuclear power when it was an emerging technology 30, 40, 50 years ago. Now it's a mature technology."

Nevertheless, the Energy Policy Act of 2005 saw the US Congress offer billions of dollars in tax breaks and loan guarantees in an attempt to kickstart construction. Although a number of utilities are pursuing licences for a total of 30 new nuclear plants in the United States, none have been approved yet. Even assuming that new subsidies were to increase US nuclear power by 1.5 times the current capacity, the result would be only an additional
510 megawatts per year from now until the year 2021. Wind power, the NRDC estimates, provides more than 1,000 megawatts a year, and that figure is likely to increase.

Another question has to do with the sustainability of the uranium supply itself. According to researchers in Australia at Monash University, Melbourne, and the University of New South Wales, Sydney, good-quality uranium ore is hard to come by. The deposits of rich ores with the highest uranium content are depleting leaving only lower-quality deposits to be exploited ${ }^{3}$. As ore quality degrades, more energy is required to mine and mill it, and greenhouse gas emissions rise. "It is clear that there is a strong sensitivity of ... greenhouse gas emissions to ore grade, and that ore grades are likely to continue to decline gradually in the medium- to long-term," conclude the researchers.

But the nuclear industry points to technological advances of its own that are likely to make nuclear power less expensive and less carbon intensive. Genoa says that new methods of mining uranium and building reactors designed to run on less uranium-rich fuel could make nuclear power even more attractive. "If we're using the same reactors in two centuries, then we've missed the boat. There are going to be other technologies," Genoa says.

Published online: 24 September 2008

doi:10.1038/climate.2008.99

References

1. Solomon, S. et al. (eds.) Climate Change 2007: The Physical Science Basis. Contribution of Working Group I to the Fourth Assessment Report of the Intergovernmental Panel on Climate Change (Cambridge University Press, Cambridge and New York, 2007); http://www.ipcc.ch/pdf/assessment-report/ ar4/wg1/ar4-wg1-spm.pdf

2. Sovacool, B. Energy Policy 36, 2950-2963 (2008)

3. Mudd, G. M. \& Diesendorf, M. Environ. Sci. Technol. 42, 2624-2630 (2008).

Kurt Kleiner is a freelance science writer. 